ISSN: 2317-2347 - Vol. 4, Ano 4, № 3 - 2015

\title{
As retraduções de La Casa De Los Espíritus: Uma (re)visita à hipótese da retradução
}

\begin{abstract}
Resumo: Este trabalho visa indagar a hipótese da retradução de Berman (1990/2007) por meio da análise de traduções já publicadas da obra La Casa de los Espíritus (1982), de Isabel Allende. Tomando por base os conceitos de retradução e de unidade de tradução, estruturas dos textos foram selecionadas com o fito de se comparar as traduções publicadas num intervalo de trinta anos e o texto-fonte. A análise se deu por um enfoque estrutural, não sendo a semântica o foco para o presente estudo. Como resultado da pesquisa, pôde-se averiguar que a hipótese da retradução não encontra respaldo na análise realizada de forma estritamente estrutural. Concluiu-se, ainda, que para que a hipótese da retradução seja averiguada é necessário que o conjunto de características, que vai desde a estilística, passando pela estrutura e alcançando a semântica, seja levado em consideração quando da aproximação ou distanciamento do texto-fonte, tal como apregoa a referida hipótese.
\end{abstract}

Palavras-chave: Retradução. Unidades de tradução. Estudos da Tradução. Tradução espanhol-português. Literatura.

\section{La Casa De Los Espíritus retranslations: (re)visiting the retranslation hypothesis}

\begin{abstract}
This paper aims to question Berman's retranslation hypothesis (1990/2007) by analyzing published translations of the book La Casa de los Espiritus, by Isabel Allende. Based on the concepts of retranslation and translation units, a number of excerpts were selected to compare the source-text with translations published in a thirty-year period. The analysis followed a structural approach, semantics not being the focus of the present study. In our research, the retranslation hypothesis could not be supported with a strictly structural analysis. Lastly, we concluded that, in order to evaluate the retranslation hypothesis, it is necessary to take into consideration certain aspects of the text, from stylistics, through structure, all the way to semantics, as that same hypothesis requires.
\end{abstract}

Keywords: Retranslation. Translation unit. Translation Studies. Translation Spanish-Portuguese. Literature.

\section{Introdução}

Esta pesquisa insere-se em um conjunto de estudos realizados no âmbito do grupo de pesquisa Tradução de Línguas Próximas, do Departamento de Línguas Estrangeiras e Tradução (LET) da Universidade de Brasília (UnB). Está vinculada ao campo disciplinar dos Estudos da Tradução, mais especificamente aos estudos descritivos orientados ao produto

\footnotetext{
${ }^{1}$ Gleiton Malta é professor do Departamento de Línguas Estrangeiras e Tradução (LET) da Universidade de Brasília (UnB) e doutor em Estudos Linguísticos, com ênfase em Estudos da Tradução, pela Faculdade de Letras da Universidade Federal de Minas Gerais (UFMG). E-mail: gleitonmalta@gmail.com.

2 Elaine Cunha Rael é bacharela em Letras Tradução-Espanhol pela Universidade de Brasília. E-mail: elaine.cunharael@gmail.com
}

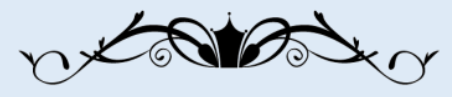




\section{Revista Letras Raras}

ISSN: 2317-2347 - Vol. 8, Ano 4, № 3 - 2015

tradutório. Com o objetivo de se indagar a hipótese da retradução (BERMAN, 1990), o corpus deste estudo é composto pelo romance La casa de los espíritus, de Isabel Allende, publicado no Chile em 1982, e por duas traduções realizadas para a língua portuguesa pelo tradutor Carlos Martins Pereira, em 1984 (3ª edição) e 2013 (43ª edição).

As retraduções, segundo Berman (1990) e Gambier (1994), são necessárias. Diversos motivos levam um texto a ser retraduzido, seja pela atualização de uma tradução que já não representa para o público atual a obra original, seja por questões comerciais, como o lançamento de novas (re)traduções em datas comemorativas. O fato é que, segundo os autores, a primeira tradução tem sempre uma tendência a ser menos altera, a ser mais assimiladora, tudo em função da legibilidade. A retradução seria, então, "um retorno ao textofonte" (GAMBIER, 1994, p. 414).

É nesse sentido que se encaixa o objetivo deste estudo, a saber: qual das duas traduções - a mais antiga ou a mais recente - se aproxima mais estruturalmente do texto-fonte (TF)? Como pressuposto, espera-se que a tradução mais antiga seja mais domesticadora que a tradução mais recente, convergindo com a hipótese da retradução (doravante HR); a tradução mais antiga deve se aproximar mais da cultura de chegada, enquanto a tradução mais recente tende a se aproximar mais da cultura de partida (BERMAN, 1990, 2007).

Diversos trabalhos foram realizados tendo a HR como tema norteador (PYM, 1998; SUSAM-SARAJEVA, 2003; PALOPOSKI; KOSKINEN, 2001; DESMIDT, 2009; O’DRISCOLL, 2009; DEANE, 2011; DASTJERDI; MOHAMMADI, 2013). No Brasil, o número 11, volume 1 de 2003 da revista Cadernos de Tradução da Universidade Federal de Santa Catarina trouxe o tema como um dos assuntos da publicação. Alguns estudos como o de Susam-Sarajeva (2003) apontam, em parte, para a refutação da hipótese de Berman; outros, como o de Paloposki e Koskinen (2001), a confirmam parcialmente. O fato é que, embora o tema tenha sido discutido por diversos estudiosos, ainda são escassos os trabalhos empíricos que comprovam ou refutem integralmente a referida hipótese. Ao lançar nosso olhar para o par linguístico espanhol-português, os estudos são ainda mais escassos.

Por outro lado, ignorar a retradução como ato permanente e importante no âmbito da tradução literária seria ignorar a realidade de diversas editoras brasileiras que investem nas retraduções ao português do Brasil de clássicos e de grandes autores da literatura hispânica; 


\section{Revista Letras Raras}

ISSN: 2317-2347 - Vol. 8, Ano 4, № 3 - 2015

consequentemente, ignorar-se-ia, também, o vasto campo de trabalho no qual novos tradutores literários podem inserir-se.

\section{Aporte teórico: a retradução e as unidades de tradução (UT)}

\subsection{A retradução}

Segundo a Routlegde Encyclopedia of translation studies (BAKER; MALMKJAER, 1998), o termo retradução, embora algumas vezes seja utilizado para se referir à tradução indireta, é mais comumente empregado para definir o ato de traduzir um trabalho que já foi previamente traduzido de uma dada língua-fonte para uma mesma língua-alvo. Para TahirGürçalar (1998, p. 233), a maioria dos trabalhos de retradução envolve textos literários, sendo a retradução, neste caso, vista como bem-vinda e inclusive necessária. Já para textos técnicos ela não somente não é comum como não é aconselhável.

O primeiro autor a dissertar sobre o tema da retradução foi Berman (1990), em seu artigo intitulado "La retraduction comme espace de la traduction”, publicado em um número da revista Palimpsestes, organizado por Bensimon (1990), dedicado à retradução. Para o autor, ao passo que as traduções envelhecem, os textos originais continuam eternamente jovens (BERMAN, 1990, p. 1). Isso ocorreria devido ao contexto histórico, social, cultural, entre outros motivos, em que as traduções e os tradutores estão inseridos. Para Berman (1990), toda tradução realizada após a primeira tradução de uma obra é uma retradução. O autor também afirma que "toda grande tradução é uma retradução", embora o contrário não seja verdadeiro. As grandes traduções estão marcadas por características que fazem com que elas não envelheçam: elas são um evento na cultura de chegada; compartilham de grande sistematicidade; são o lugar de encontro entre a língua-fonte e a língua-alvo; criam um vínculo intenso com o original; dentro da atividade do tradutor são um precedente incontornável, e são retraduções (BERMAN, 1990, p. 3).

Para Berman (2007, p. 96) as retraduções se encontram em posição privilegiada, em oposição tanto ao texto original quanto à primeira tradução; elas se aproximariam mais do texto original do que as traduções, já que gozariam da possibilidade de averiguar o que foi

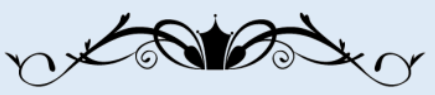




\section{Revista Letras Raras}

ISSN: 2317-2347 - Vol. 8, Ano 4, № 3 - 2015

apagado nas traduções e de utilizar o que foi exitoso nelas. Ou seja, quanto mais recente uma retradução, mais próxima ela está do original.

Gambier (1994) e Bensimon (1990) corroboram essa teoria ao afirmarem que, levando em conta o contexto cultural e editorial da cultura alvo, as primeiras traduções tendem a suprimir a alteridade do texto traduzido e a fazer mudanças motivadas pela preocupação com a aceitação e legibilidade do texto (GAMBIER, 1994, p. 414). As primeiras traduções têm como objetivo adaptar os trabalhos estrangeiros e introduzi-los na cultura de chegada (BENSIMON, 1990, p. ix). Para Gambier (1994) a tradução é um ato sujeito ao tempo, não somente ao tempo referente à recepção da tradução na língua-alvo, mas também à própria duração do processo de traduzir. Devido a isso, a tradução é sempre uma atividade inacabada, que necessita repetição (GAMBIER, 1994). A retradução, portanto, tem como meta restituir o tom e o ritmo do original, observando as necessidades na cultura de chegada. Gambier (1994) sustenta, ainda, que a publicação de uma retradução não significa que a tradução anterior se torne inaceitável. E não é devido ao fato de uma retradução vir posteriormente a uma primeira tradução que aquela tenha esta como ponto de partida. A retradução pode partir diretamente do texto-fonte.

Contudo, a HR ainda é ponto divergente entre os estudiosos. Para Pym (1998), um dos motivos que levam às retraduções é o fato de as traduções de um mesmo texto serem muito divergentes, especialmente quando o texto é muito complexo (PYM, 1998, p. 83). O autor classifica como "retraduções passivas" aquelas que não causam incômodo na cultura de chegada, que foram realizadas em períodos distantes e a fronteira geopolítica e cultural entre elas também é distante. O contrário desse tipo de retradução é a "retradução ativa", ou seja, traduções localizadas no mesmo contexto cultural ou geracional e que causam desacordo entre elas. No primeiro caso, a retradução passiva refere-se a retraduções de um mesmo texto-fonte produzidas numa mesma época, mas em diferentes lugares e culturas. $\mathrm{O}$ fato de serem retraduções separadas por fronteiras, sejam elas geográficas ou dialéticas, faz com que não haja competição entre elas. Já as retraduções ativas ocorrem em uma mesma cultura.

Nesta pesquisa estudam-se as retraduções ativas, já que as retraduções analisadas foram realizadas no Brasil em épocas diferentes. Porém, ainda que sejam ativas, não há necessariamente uma competição entre elas, pois cada uma visou suprir as necessidades de sua época. E, como afirma Gambier (1994), uma tradução mais recente pode ser melhor no

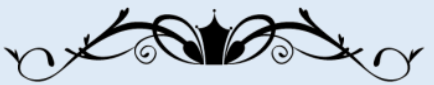




\section{Revista Letras Raras}

ISSN: 2317-2347 - Vol. 8, Ano 4, № 3 - 2015

sentido de se aproximar mais do texto-fonte, mas não pode fazer com que a tradução anterior se torne inaceitável.

Para Susam-Sarajeva (2003), a ideia de recuperação do que foi perdido pode ser fruto de crenças. A autora elenca uma série de tópicos pelos quais não há dados empíricos que comprovem o postulado pelo modelo de progressão histórica: (i) a suposição de que a primeira tradução é mais assimiladora, enquanto a retradução é mais altera. A autora advoga que ambas as características podem ser encontradas tanto em traduções como em retraduções. (ii) A lacuna de tempo entre uma tradução e o surgimento da retradução. Nesse caso, a autora se justifica dando exemplos de obras que foram retraduzidas imediatamente depois de serem traduzidas. Assevera, também, que (iii) o argumento de que uma retradução é demandada porque a primeira tradução sempre é deficiente, assimiladora, literal, entre outros, não é forte o suficiente, já que outros motivos, inclusive de natureza extratradutória, podem fomentar a realização de retraduções. A autora contesta (iv) a ideia de que uma retradução só é demandada pela necessidade da cultura-meta; se assim o fosse, o TF não teria nada de interessante para ser retraduzido. A autora chama à reflexão sobre o fato de que a inexistência de uma retradução não quer dizer, em absoluto, que a tradução existente não seja boa.

Paloposki e Koskinen (2010) asseveram que a questão da tradução é muito mais complexa que a hipótese conjeturada por Berman. A domesticação de traduções, por exemplo, pode ser uma característica muito mais ligada à fase pela qual a literatura de uma nação passou que à HR propriamente dita. Por outro lado, ainda segundo as autoras, a orientação do texto-fonte ao texto-alvo pode estar diretamente ligada à história em algum momento (seja passado, presente ou futuro), ou à demanda do público de chegada onde a (re)tradução será realizada (PALOPOSKI; KOSKINEN, 2010, p. 32).

Geralmente são os grandes clássicos que são retraduzidos ou reimpressos. Em estudo realizado em 2003, Paloposki e Koskinen observam que alguns clássicos são retraduzidos e outros não. Asseveram que nem tudo pode ser retraduzido, ou seja, muitas vezes há de se escolher o que retraduzir e o que reimprimir, evitando assim gastos exorbitantes de edição. Segundos as autoras, essa escolha entre a retradução e a reimpressão parece ser aleatória (PALOPOSKI; KOSKINEN, 2010, p. 34). Contudo, observam que em determinados momentos editoras jovens preferem as retraduções enquanto as mais antigas (maiores) preferem as reimpressões - que não deixam de ser retraduções. Isso se dá pelo fato de as

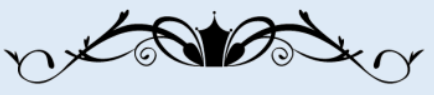




\section{Revista Letras Raras}

ISSN: 2317-2347 - Vol. 8, Ano 4, № 3 - 2015

primeiras não possuírem retraduções publicadas, enquanto as segundas, sim. Outro ponto a favor da retradução está no marketing positivo que ela possibilita, ou seja, retraduções atraem mais publicidade que novas traduções (PALOPOSKI; KOSKINEN, 2010, p. 35). Portanto, os motivos que levam à edição de uma retradução, atualmente, são de cunho muito mais editoriais e mercadológicos, que de outra ordem. No caso da obra analisada neste artigo, La casa de los espíritus, já ultrapassou mais de 40 edições, entre retraduções e reimpressões, desde seu lançamento em 1982. O mesmo ocorre com outras obras do vasto e exitoso rol da literatura em língua espanhola, cujos autores consagrados também têm na retradução um dos motivos do sucesso de vendas de suas obras no território nacional.

A retradução foi investigada sob a perspectiva da abordagem processual da tradução. Malta (2015), modela o processo de retradução com base em dados de rastreamento ocular, registro de teclado e mouse e protocolos retrospectivos. Como resultados, o modelo processual da retradução proposto pelo autor revela acesso majoritário ao TA e minoritário às traduções que serviram de insumo no experimento. Isso significa que a relação de tradução entre TA-TF foi maior que a registrada nas traduções.

\subsection{As unidades de tradução (UT)}

"Unidades de tradução" é o termo utilizado por pesquisadores dos Estudos da Tradução para a segmentação textual de textos-fonte (TF) e textos-alvo (TA). A delimitação destes segmentos depende diretamente da orientação para a segmentação, ou seja, se está orientada para o produto ou para o processo, e surgiu da necessidade de se seccionar os textos, tanto no processo tradutório capturado em tempo real como para a comparação entre o texto traduzido e o texto original, e vice-versa.

Do ponto de vista do produto, Vinay e Darbelnet foram os primeiros a definir as UT como "o menor segmento do discurso cujos signos estão ligados de tal maneira que não devem ser traduzidos de forma separada"3 (VINAY; DARBELNET, 1977, p. 37). Segundo Kenny (2009, p. 304), a definição dos autores foi criticada por ser demasiadamente prescritiva, tendo como foco a língua-fonte e apoiando-se em uma tradução idealizada, o que limita a capacidade da teoria para explicar a realidade que envolve uma tradução.

\footnotetext{
${ }^{3}$ Tradução de: l'unité de traduction est le plus petit segment de l'énoncé dont la cohésion des signes est telle qu'ils ne doivent pas être traduits séparément.
}

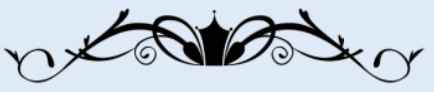




\section{Revista Letras Raras}

ISSN: 2317-2347 - Vol. 8, Ano 4, № 3 - 2015

Do ponto de vista linguístico, mas também voltado ao produto, Catford (1980), apesar de não citar explicitamente o termo UT, investiga a segmentação textual por meio de seus equivalentes textuais e correspondentes formais. Os primeiros são considerados como qualquer $\mathrm{TF}$ ou segmento de $\mathrm{TF}$ que pode ser identificado com um determinado TA ou segmento do TA (CATFORD, 1980, p. 29). Já um correspondente formal é qualquer categoria linguística da língua fonte que pode ser identificada com outra categoria da língua alvo, ocupando, sempre que possível, o mesmo espaço dentro da estrutura (economia) de ambos os sistemas linguísticos (CATFORD, 1980, p. 29). Neste caso, observa-se que o autor não se limita a tamanho de UT.

Para Toury (1995), a UT só pode ser definida ad hoc, nunca previamente. O estabelecimento da UT se dá, segundo o autor, por meio de um processo de pareamento, utilizando o princípio no leftovers (sem sobras), no qual segmentos do TA são correlacionados com segmentos do TF. Porém, essa correlação que o autor chama de pares acoplados (coupled pairs) tem seus limites difíceis de serem delimitados devido à sua natureza dinâmica e alta subordinação ao contexto. Contudo, é importante que a unidade escolhida seja "relevante para a operação que nela será realizada" (TOURY, 1995, p. 88), já que esta correlação está baseada em um processo de problema-solução.

Os segmentos do TF e os do TA, segundo Toury, não precisam estar na mesma sequência nos referidos textos, e resultam de um processo retrospectivo de comparação. A delimitação da UT visa à reconstrução gradual das decisões tradutórias e, por sua análise iniciar-se pelo TA, tem a perspectiva voltada para ele e não para o TF (TOURY, 1995). Esta é a mudança mais expressiva comparada com os outros autores no que diz respeito às UT, pois, até então, os teóricos as relacionavam sempre com o TF e Toury as relaciona com o TA.

Do ponto de vista do processo tradutório, a UT se reveste de algumas diferenças com relação à sua definição quando orientada ao produto. No segundo caso, a UT está intimamente ligada com o TA; já no primeiro caso, com orientação ao processo, o TF é o alvo de atenção para as análises. Neste sentido, os métodos para delimitá-la tendo como perspectiva o processo e o produto, bem como suas definições e utilidades, são bem distintos.

Neste estudo, o conceito de UT será utilizado tanto como pressuposto teórico como metodologia. As unidades serão analisadas do ponto de vista do produto, isto é, foram mapeadas já na tradução e na retradução e depois no TF. Será utilizado um enfoque estrutural,

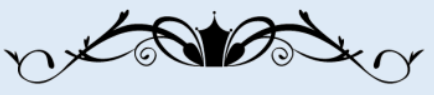




\section{Revista Letras Raras}

ISSN: 2317-2347 - Vol. 8, Ano 4, № 3 - 2015

mas também lançaremos mão de algumas observações de uma perspectiva semântica, o que será explicado mais detalhadamente junto aos dados.

\section{Da metodologia}

\subsection{Do objeto de estudo}

Como anunciado na Introdução, o objeto de estudo deste trabalho é a obra La casa de los espíritus, de Isabel Allende, e as duas traduções realizadas para o português do Brasil (PB)

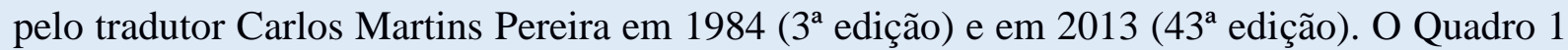
a seguir apresenta as principais características técnicas do capítulo analisado.

Quadro 1 - Ficha técnica do capítulo analisado.

\begin{tabular}{l|c|c|c}
\hline \multicolumn{5}{c}{ Ficha técnica } \\
\hline & $\begin{array}{l}\text { ORIGINAL } \\
\text { (1982, Casa de } \\
\text { las Américas) }\end{array}$ & $\begin{array}{l}\text { Tradução 1 } \\
(1984, \text { DIFEL) }\end{array}$ & $\begin{array}{l}\text { Tradução 2 } \\
\text { 2013, } \\
\text { BERTRAND } \\
\text { BRASIL) }\end{array}$ \\
\hline $\begin{array}{l}\text { Número de palavras } \\
\text { Número de } \\
\text { caracteres }\end{array}$ & 15.690 & 14.703 & 14.634 \\
\hline $\begin{array}{l}\text { Número } \\
\text { parágrafos }\end{array}$ & 73.962 & 71.742 & 72.712 \\
\hline
\end{tabular}

La casa de los espíritus foi publicada no Chile em 1982, e sua primeira tradução para o português do Brasil data de 1984. O romance conta a história de três gerações de uma família no decorrer do turbulento século XX, com ênfase nas mulheres. A história tem início na primeira década do século XX e se finda com o golpe militar de 1973, que derrubou o presidente Salvador Allende. Foi um momento revolucionário no país e esse clima de revolução está bastante presente na obra, tanto política como socialmente. Há, ainda, forte presença da igreja católica e do movimento feminista.

Além do contexto histórico também há o elemento fantasioso, com a presença do sobrenatural e da ficção. A menina Clara, filha de Severo del Valle e caçula de muitos irmãos, possui o dom (ou a maldição) da clarividência e da cinestesia. Quando já está mais moça, casa-se com Esteban Trueba, latifundiário e político, homem de temperamento agressivo e amargurado. Desse casamento nasce Branca, e esta, quando adulta, tem uma filha chamada Alba. O livro é extenso e detalha a vida de cada uma dessas gerações de personagens, seus

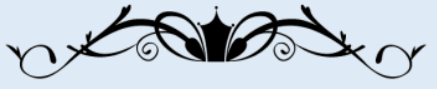




\section{Revista Letras Raras}

ISSN: 2317-2347 - Vol. 8, Ano 4, № 3 - 2015

conflitos internos e externos, acontecimentos cotidianos, e a sociedade de cada época. Neste artigo, apresentamos os dados relativos somente ao primeiro capítulo da narrativa, já que este trata de apresentar os personagens da primeira geração e o contexto em que estão inseridos.

\subsection{Da coleta dos dados}

Os dados foram coletados simultaneamente nas duas traduções estudadas. Por meio da leitura paralela dos dois textos, foram sendo observadas as diferenças estruturais - isto é, a ordem em que as palavras aparecem, a classe gramatical, a omissão ou o acréscimo de termos - e estas, mapeadas como UT. Sempre que alguma divergência entre as traduções era detectada, eram anotadas em uma tabela. Ressalte-se que o mapeamento das UT não se restringiu a essa ou àquela classe gramatical, ou a algum tamanho em especial. Elas começam onde surgem as diferenças entre os dois textos, e terminam onde estas diferenças também acabam. Podem ser apenas uma palavra, duas ou mais palavras consecutivas que aparecem em ordem diferente, ou um termo que em uma das traduções é apenas uma palavra enquanto na outra tradução foi substituído por uma locução equivalente.

Acrescentou-se, ainda, os termos adjacentes, estes sim no nível da frase ou da oração, ou uma estrutura menor, como um sujeito ou um complemento, para contextualizar as UT e facilitar a compreensão. Porém, há também momentos em que a unidade se constitui em todo o conteúdo de uma célula do quadro, como na categoria inversão (as categorias serão apresentadas a seguir), na qual apenas um termo é destacado para facilitar a observação de seu deslocamento nos trechos estudados. Posteriormente, as UT selecionadas foram comparadas aos trechos correspondentes do texto-fonte, que também compõem os quadros.

Ao final, será feita uma análise quantitativa, linha por linha, para definir qual tradução aproxima-se mais do original por este viés estrutural, e determinar se a hipótese da retradução pode ser aplicada também por este enfoque. Vale ressaltar aqui que a retradução não utilizou nenhum suporte de memória de tradução.

Com o mapeamento, foram criadas categorias de comparação estritamente estruturais: (i) categoria numeral, (ii) categoria advérbio, (iii) categoria inversões, (iv) categoria acréscimos e omissões, (v) categoria nomes próprios, e (vi) categoria traduções divergentes.

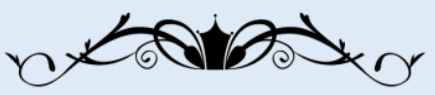




\section{Revista Letras Raras}

ISSN: 2317-2347 - Vol. 8, Ano 4, № 3 - 2015

(i) Numeral - corresponde às diferenças observadas com relação à escrita do numeral, variando entre escrita por extenso ou utilização de algarismos arábico e romano.

(ii) Advérbio - observou-se que, enquanto uma das traduções utilizava locuções ou adjetivos, a outra optou pela correspondência através de advérbios terminados com o sufixo -MENTE.

(iii) Inversões - trata-se das inversões entre sujeito e predicado, sujeito e verbo, objeto e adjunto adnominal, etc.

(iv) Acréscimos e omissões - em geral, apenas um termo que foi retirado ou acrescido a uma das traduções.

(v) Nomes próprios - nomes de personagens, locais e regiões.

(vi) Traduções divergentes - uma categoria que não se encaixa em nenhuma outra, e que abrange todas as demais diferenças estruturais observadas. Aqui foram registradas as diferenças encontradas quanto ao uso de palavras consideradas sinônimas, ou de termos que, embora pertençam à mesma classe, possuem significados um pouco distintos. Foram observados muitos casos em que o termo em espanhol existe em português com o mesmo significado, e que uma das traduções o manteve, enquanto a outra optou por um termo semelhante ou mesmo não tão próximo do original. Os quadros e as análises aqui propostas são o tema das seguintes subseções.

\section{Apresentação e discussão dos dados}

A seguir, serão apresentados os quadros com as unidades de tradução coletadas para análise. As traduções de 1984 e 2013 serão nomeadas, respectivamente, T1 e T2. Os quadros a seguir estão separados de acordo com o tipo de estrutura selecionada, referente ao léxico, à classe de palavras e ao tipo de diferença estrutural, e abaixo de cada quadro estão os comentários referentes aos dados.

Quadro 2 - categoria numeral

\begin{tabular}{l|l|l}
\hline \multicolumn{1}{c|}{ TF } & \multicolumn{1}{c|}{ T1 } & \multicolumn{1}{c}{ T2 } \\
\hline $\begin{array}{l}\text { Cincuenta años después } \\
(\ldots)\end{array}$ & Cinqüenta anos depois & $\mathbf{5 0}$ anos depois $(\ldots)$ \\
\hline Durante la misa de doce & Durante a missa das doze & $\begin{array}{l}\text { Durante a missa das } \\
\mathbf{1 2}\end{array}$ \\
\hline
\end{tabular}

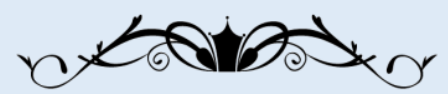




\section{Revista Letras Raras}

ISSN: 2317-2347 - Vol. 8, Ano 4, № 3 - 2015

\begin{tabular}{l|l|l}
\hline \multicolumn{1}{c|}{ TF } & \multicolumn{1}{c}{ T1 } & \multicolumn{1}{c}{ T2 } \\
\hline $\begin{array}{l}\text { Luchaba desde hacía diez } \\
\text { años }\end{array}$ & Lutava fazia dez anos & Lutava há 10 anos \\
\hline $\begin{array}{l}\text { Había dado a luz quince } \\
\text { hijos }\end{array}$ & $\begin{array}{l}\text { Tinha dado à luz quinze } \\
\text { filhos }\end{array}$ & Dera à luz 15 filhos \\
\hline $\begin{array}{l}\text { De los cuales todavía } \\
\text { quedaban once vivos }\end{array}$ & $\begin{array}{l}\text { Onze dos quais restavam } \\
\text { ainda vivos }\end{array}$ & $\begin{array}{l}\text { Dos quais, entretanto, } \\
\text { só 11 estavam vivos }\end{array}$ \\
\hline $\begin{array}{l}\text { Clara, la menor, tenía } \\
\text { diez años }\end{array}$ & $\begin{array}{l}\text { Clara, a mais nova, tinha } \\
\text { dez anos }\end{array}$ & $\begin{array}{l}\text { Clara, a mais nova, já } \\
\text { estava com } \mathbf{1 0} \text { anos }\end{array}$ \\
\hline $\begin{array}{l}\text { A los dieciocho años (...) } \\
\text { Siglo veinte, el siglo de } \\
\text { las luces }\end{array}$ & $\begin{array}{l}\text { Século vinte, o século } \\
\text { das luzes }\end{array}$ & $\begin{array}{l}\text { Século XX, o século } \\
\text { das luzes }\end{array}$ \\
\hline $\begin{array}{l}\text { La joven se casó de la } \\
\text { noche a la mañana con } \text { con }\end{array}$ & $\begin{array}{l}\text { A jovem se casou de um } \\
\text { dia para o outro com um } \\
\text { diplomata vinte anos diplomático veinte } \\
\text { años mayor }\end{array}$ & $\begin{array}{l}\text { A jovem se casou da } \\
\text { noite para o dia com } \\
\text { um diplomata } \mathbf{2 0} \text { anos } \\
\text { mais velho }\end{array}$ \\
\hline \multicolumn{2}{|c|}{ mais velho } \\
\hline
\end{tabular}

Observando os dados do Quadro 2, vê-se que a T1 mantém os números escritos por extenso, enquanto na T2 são utilizados algarismos arábicos e romanos (este último apenas quando referente a século). Um dos possíveis motivos que levaram a essa diferenciação é a exigência do encargo, no caso, a editora. Outra possibilidade é a escolha do próprio tradutor, que pode ter realizado a mudança por acreditar que dessa forma o texto ficaria mais compatível com uma escrita mais contemporânea, ou simplesmente por ter mudado sua estilística. Nesta categoria, portanto, a T1 aproxima-se mais do TF que a T2.

Com relação à categoria advérbio, esta classe de palavras será analisada somente quanto à ausência ou utilização do sufixo -MENTE. No total de exemplos coletados, todas as UT da T1 optam por não utilizar o sufixo, enquanto todas as UT da T2 o utilizam. Considerando o total de 16 UT do TF, sendo 14 com a ausência e apenas 2 com a presença do sufixo, tem-se que, nesta categoria, a T1 também aproxima-se mais do TF, tal como ocorreu com a categoria numeral (ver Quadro 3).

Quadro 3 - Categoria advérbio

\begin{tabular}{l|l|lr}
\hline \multicolumn{1}{c}{ TF } & \multicolumn{1}{c}{ T1 } & \multicolumn{2}{c}{ T2 } \\
\hline $\begin{array}{l}\text { Sacerdote se extendía } \\
\text { demasiado en los } \\
\text { pecados }\end{array}$ & $\begin{array}{l}\text { Sacerdote se estendia } \\
\text { demasiado pelos } \\
\text { pecados }\end{array}$ & $\begin{array}{l}\text { Sacerdote } \\
\text { exageradamente } \\
\text { pecados }\end{array}$ & $\begin{array}{r}\text { insistia } \\
\text { nos }\end{array}$ \\
\hline $\begin{array}{l}\text { Marcos se hundió en la } \\
\text { depresión }\end{array}$ & $\begin{array}{l}\text { Marcos afundou-se na } \\
\text { depressão }\end{array}$ & $\begin{array}{l}\text { Marcos } \\
\text { profundamente } \\
\text { deprimido }\end{array}$ & ficou \\
\hline $\begin{array}{l}\text { Nívea lloró } \\
\text { desconsoladamente }\end{array}$ & $\begin{array}{l}\text { Nívea } \\
\text { inconsolável }\end{array}$ & $\begin{array}{l}\text { Nivea chorou } \\
\text { inconsolavelmente }\end{array}$ \\
\hline $\begin{array}{l}\text { Repartieron } \\
\text { equitativamente } \\
\text { ganancias }\end{array}$ & $\begin{array}{l}\text { Dividiram os ganhos ao } \\
\text { meio }\end{array}$ & $\begin{array}{l}\text { Dividiram } \\
\text { equitativamente } \\
\text { ganhos }\end{array}$ & os \\
\hline
\end{tabular}

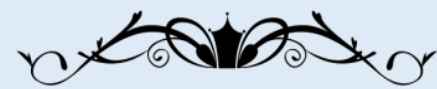




\section{Revista Letras Raras}

ISSN: 2317-2347 - Vol. 8, Ano 4, № 3 - 2015

\begin{tabular}{|c|c|c|}
\hline \multicolumn{3}{|c|}{ Quadro 4 - Categoria advérbio (continua) } \\
\hline TF & T1 & T2 \\
\hline $\begin{array}{l}\text { Podía describir con } \\
\text { detalle }\end{array}$ & $\begin{array}{l}\text { Podia descrever com } \\
\text { pormenor }\end{array}$ & $\begin{array}{l}\text { Era capaz de descrever } \\
\text { detalhadamente }\end{array}$ \\
\hline $\begin{array}{l}\text { Hasta que fueron } \\
\text { quemados por error }\end{array}$ & $\begin{array}{l}\text { Até que foram } \\
\text { queimados por engano }\end{array}$ & $\begin{array}{l}\text { Até } \\
\text { equivocadamente } \\
\text { queimados }\end{array}$ \\
\hline $\begin{array}{l}\text { Retirando } \\
\text { delicadeza }\end{array}$ & Com delicadeza, tirar & Delicadamente retirando \\
\hline Ordenaba por fechas & Ordenava por datas & $\begin{array}{l}\text { Organizava } \\
\text { cronologicamente }\end{array}$ \\
\hline $\begin{array}{l}\text { Com el tiempo, me } \\
\text { aceptó por esposo }\end{array}$ & $\begin{array}{l}\text { Com o tempo, me } \\
\text { aceitou por esposo }\end{array}$ & $\begin{array}{ll}\text { Posteriormente, } & \text { me } \\
\text { aceitou como marido } & \end{array}$ \\
\hline $\begin{array}{l}\text { El obispo en persona le } \\
\text { advirtió }\end{array}$ & $\begin{array}{l}\text { O bispo em pessoa o } \\
\text { advertir }\end{array}$ & $\begin{array}{l}\mathrm{O} \quad \text { bispo } \\
\text { pessoalmente }\end{array}$ \\
\hline $\begin{array}{l}\text { Clara, que estaba } \\
\text { demasiado } \\
\text { impresionada }\end{array}$ & $\begin{array}{l}\text { Porque a viu } \\
\text { demasiado } \\
\text { impressionada }\end{array}$ & $\begin{array}{l}\text { Clara, que } \\
\text { extremamente } \\
\text { impressionada }\end{array}$ \\
\hline $\begin{array}{l}\text { El ayudante, demasiado } \\
\text { emocionado }\end{array}$ & $\begin{array}{l}\text { O ajudante, demasiado } \\
\text { emocionado }\end{array}$ & $\begin{array}{l}\mathrm{O} \\
\text { extremamente } \\
\text { emocionado }\end{array}$ \\
\hline $\begin{array}{l}\text { Estaban vestidas de } \\
\text { negro riguroso }\end{array}$ & $\begin{array}{l}\text { Estavam vestidas de } \\
\text { negro rigoroso }\end{array}$ & $\begin{array}{l}\text { Estavam rigorosamente } \\
\text { vestidas de negro }\end{array}$ \\
\hline No sabía que así mismo & $\begin{array}{l}\text { Não sabia que assim } \\
\text { mesmo }\end{array}$ & $\begin{array}{lcc}\text { Não } & \text { sabia } \\
\text { exatamente assim }\end{array}$ \\
\hline $\begin{array}{l}\text { Verlos con } \\
\text { antecipación }\end{array}$ & $\begin{array}{l}\text { Ver com alguma } \\
\text { antecipação }\end{array}$ & Vê-los antecipadamente \\
\hline $\begin{array}{l}\text { Todo estaba oscuro y } \\
\text { silencioso }\end{array}$ & $\begin{array}{l}\text { Tudo estava escuro e } \\
\text { silencioso }\end{array}$ & $\begin{array}{l}\text { Completamente escura e } \\
\text { silenciosa }\end{array}$ \\
\hline
\end{tabular}

Observando mais atentamente as estruturas além dos advérbios apresentados no Quadro 3, percebe-se também que na T1 não só os advérbios se aproximam mais do TF, mas o conjunto como um todo. Na T1, o tradutor preferiu uma tradução mais palavra-por-palavra; em contrapartida, na T2, ele realizou algumas mudanças, talvez no intuito de afastar-se mais das estruturas e palavras típicas da língua espanhola e aproximar-se mais da semântica do TF. Um exemplo disso é a palavra "demasiado", que frequentemente é trocada por “exageradamente". Ambas as palavras existem na língua portuguesa, mas "demasiado" é um termo tipicamente hispânico observado de forma bem mais recorrente num falante de língua espanhola do que de língua portuguesa.

Quadro 5 - categoria inversões

\begin{tabular}{l|l|l}
\hline \multicolumn{3}{c}{ Q Quadro 4- categoria inversões (continua) } \\
\hline \multicolumn{1}{c|}{ T1 } & \multicolumn{1}{c}{ T2 } \\
\hline Que llegó Barrabás & Que chegou Barrabás & Que Barrabás chegou \\
\hline $\begin{array}{l}\text { Venía en una jaula } \\
\text { indigna }\end{array}$ & $\begin{array}{l}\text { Vinha numa jaula } \\
\text { indigna }\end{array}$ & $\begin{array}{l}\text { Vinha num indigno } \\
\text { engradado }\end{array}$ \\
\hline $\begin{array}{l}\text { Se erguían amenazantes } \\
\text { bultos }\end{array}$ & $\begin{array}{l}\text { Erguiam-se } \\
\text { ameaçadores }\end{array}$ & $\begin{array}{l}\text { Vultos ameaçadores } \\
\text { erguiam-se }\end{array}$ \\
\hline
\end{tabular}

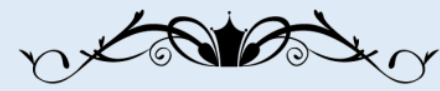




\section{Revista Letras Raras}

ISSN: 2317-2347 - Vol. 8, Ano 4, № 3 - 2015

\begin{tabular}{|c|c|c|}
\hline \multicolumn{3}{|c|}{ Quadro 4 - categoria inversões (continua) } \\
\hline TF & T1 & T2 \\
\hline $\begin{array}{l}\text { Habia cedido el ímpeto de } \\
\text { su asombrosa fertilidad }\end{array}$ & $\begin{array}{l}\text { Tinha acabado o ímpeto } \\
\text { da sua fertilidade } \\
\text { assombrosa }\end{array}$ & $\begin{array}{l}\text { Acabara o ímpeto de } \\
\text { sua fantástica } \\
\text { fertilidade }\end{array}$ \\
\hline $\begin{array}{lr}\text { Imaginación } & \text { que } \\
\text { heredaron todas las } \\
\text { mujeres de su familia por } \\
\text { vía materna }\end{array}$ & $\begin{array}{l}\text { Imaginação herdada, via } \\
\text { materna, por todas as } \\
\text { mulheres da família }\end{array}$ & $\begin{array}{l}\text { Imaginação que todas } \\
\text { as mulheres da família } \\
\text { herdaram por via } \\
\text { materna }\end{array}$ \\
\hline $\begin{array}{l}\text { La responsabilidad de su } \\
\text { hermosura pasaría a otras } \\
\text { manos }\end{array}$ & $\begin{array}{l}\text { Passando dessa maneira } \\
\text { a responsabilidade da sua } \\
\text { formosura para outras } \\
\text { mãos }\end{array}$ & $\begin{array}{l}\text { A responsabilidade de } \\
\text { sua formosura } \\
\text { passaria a outras mãos }\end{array}$ \\
\hline $\begin{array}{l}\text { Lo habían discutido a } \\
\text { menudo con sus amigas } \\
\text { sufragistas }\end{array}$ & $\begin{array}{l}\text { Tinham discutido isso } \\
\text { muitas vezes, ela e as } \\
\text { amigas sufragistas }\end{array}$ & $\begin{array}{l}\text { Muitas vezes, ela e as } \\
\text { amigas sufragistas } \\
\text { haviam discutido o } \\
\text { assunto }\end{array}$ \\
\hline Escucharon su terrible voz & Ouviram sua terrível voz & $\begin{array}{lll}\begin{array}{l}\text { Ouviram } \\
\text { terrível }\end{array} & \text { sua } & \text { voz } \\
\end{array}$ \\
\hline $\begin{array}{l}\text { Los esposos del Valle } \\
\text { fueron los primeros en } \\
\text { reaccionar }\end{array}$ & $\begin{array}{l}\text { Os esposos del Valle } \\
\text { foram os primeiros a } \\
\text { reagir }\end{array}$ & $\begin{array}{l}\mathrm{O} \text { casal del Valle } \\
\text { reagiu antes de todos }\end{array}$ \\
\hline $\begin{array}{l}\text { Se le acortó la pierna } \\
\text { izquierda }\end{array}$ & $\begin{array}{l}\text { Encurtou-se-lhe a perna } \\
\text { esquerda }\end{array}$ & $\begin{array}{l}\text { Sua perna esquerda } \\
\text { encurtou }\end{array}$ \\
\hline $\begin{array}{l}\text { Y le había tocado } \\
\text { enterrarlo en una ocasión } \\
\text { anterior }\end{array}$ & $\begin{array}{l}\text { Já numa outra ocasião } \\
\text { fora encarregada de } \\
\text { enterrá-lo }\end{array}$ & $\begin{array}{l}\text { Já lhe coubera enterrá- } \\
\text { lo em ocasião } \\
\text { anterior }\end{array}$ \\
\hline $\begin{array}{l}\text { Apoyado en una escopeta } \\
\text { de dos cañones de modelo } \\
\text { antiguo }\end{array}$ & $\begin{array}{l}\text { Apoiado a uma } \\
\text { espingarda de dois canos } \\
\text { modelo antigo }\end{array}$ & $\begin{array}{l}\text { Apoiado num modelo } \\
\text { antigo de espingarda } \\
\text { de dois canos }\end{array}$ \\
\hline $\begin{array}{l}\text { Bajo la escoba implacable } \\
\text { de la Nana }\end{array}$ & $\begin{array}{l}\text { Debaixo da vassoura } \\
\text { implacável da Ama }\end{array}$ & $\begin{array}{l}\text { Sob a implacável } \\
\text { vassoura da Nana }\end{array}$ \\
\hline $\begin{array}{l}\text { Ensenaba a hablar en } \\
\text { español a un loro cuya } \\
\text { lengua materna era de } \\
\text { origen amazónico }\end{array}$ & $\begin{array}{l}\text { Ensinava espanhol a um } \\
\text { papagaio cuja língua } \\
\text { materna era de origem } \\
\text { amazônica }\end{array}$ & $\begin{array}{l}\text { Ensinava um papagaio } \\
\text { cuja língua materna } \\
\text { era de origem } \\
\text { amazônica a falar } \\
\text { espanhol }\end{array}$ \\
\hline
\end{tabular}

Esta categoria foi uma das mais ricas em exemplos. Em números, foi um total de 66 UTs, sendo que neste trabalho, por motivo de espaço, apresentamos somente 14. Levando em consideração o número total (66) e apenas a parte destacada, tem-se que a T1 possui 51 estruturas que se aproximam mais do TF, contra apenas 15 da T2.

Ao se analisar a estrutura inteira dentro de cada célula, 31 exemplos da T2, quase metade do total de exemplos, foge da estrutura original do TF. Isto é, além das inversões existentes, há também outras diferenças no tocante à classe gramatical dos termos ou na escolha do vocabulário. Em oposição a isso, somente 11 estruturas da T1 trazem diferenças maiores com relação ao TF.

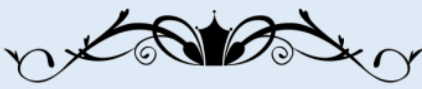




\section{Revista Letras Raras}

ISSN: 2317-2347 - Vol. 8, Ano 4, № 3 - 2015

Há muitos casos de inversão referentes à ordem “substantivo - adjetivo". Esta é considerada a ordem direta, e quando o adjetivo é anteposto, em geral, é para enfatizá-lo ou por escolha estilística. A seguir serão enumerados alguns casos nos quais o tradutor optou pela anteposição do adjetivo em oposição ao TF:

- Indigno engradado

- Implacável vassoura

- Grandioso funeral

- Prodigioso tio

- Infame fogueira

- Incontroláveis movimentos

- Rosado e monumental porco assado

- Incrível visão

- Alvíssimas pernas

Totalizam-se nove casos em que a T2 se distancia mais do TF. Há, porém, outros cinco exemplos em que a T1 modificou a ordem do TF, e o T2 a retomou, como por exemplo:

asombrosa fertilidad - fertilidade assombrosa (T1) - fantástica fertilidade (T2)

Acima temos uma das linhas da tabela, seguindo a ordem $\mathrm{TF}-\mathrm{T} 1-\mathrm{T} 2$, em que se observa a inversão dos termos na T1, e a retomada da estrutura original na T2. No entanto, apesar de manter a ordem sintática, a T2 utiliza o vocábulo "fantástica", e a T1 realiza a tradução literal "assombrosa".

Outro caso é o do deslocamento de conjunções adversativas. Há cinco casos nos quais no TF há uma conjunção adversativa no início do período, e que foi deslocada e posta entre vírgulas na T2. A T1, em contrapartida, mantém a ordem do original nestes exemplos, e há apenas 1 caso em que a T1 muda a ordem dos termos, e a T2 retoma a estrutura do TF.

Quadro 6 - categoria acréscimos e omissões

\begin{tabular}{l|l|l}
\hline \multicolumn{3}{c}{ Quadro 5 - categoria acréscimos e omissões (continua) } \\
\hline \multicolumn{1}{c|}{ TF } & \multicolumn{1}{c}{ T1 } & \multicolumn{1}{c}{ T2 } \\
\hline $\begin{array}{l}\text { Había dado a luz quince } \\
\text { hijos, de los cuales }\end{array}$ & $\begin{array}{l}\text { Tinha dado a luz quinze } \\
\text { filhos, onze dos quais }\end{array}$ & $\begin{array}{l}\text { Dera a luz a 15 filhos, } \\
\text { dos quais, entretanto, só }\end{array}$ \\
todavía quedaban once & restavam ainda vivos & 11 estavam vivos \\
\hline
\end{tabular}

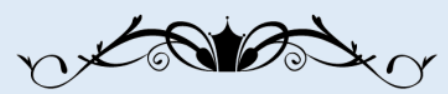




\section{Revista Letras Raras}

ISSN: 2317-2347 - Vol. 8, Ano 4, № 3 - 2015

\begin{tabular}{|c|c|c|}
\hline \multicolumn{3}{|c|}{ Quadro 5 - categoria acréscimos e omissões (continua) } \\
\hline TF & T1 & $\mathbf{T 2}$ \\
\hline \multicolumn{3}{|l|}{ vivos } \\
\hline $\begin{array}{l}\text { Tenía razones para } \\
\text { suponer que ya estaba } \\
\text { acomodándose en la } \\
\text { madurez, pues su hija } \\
\text { Clara, la menor, tenía } \\
\text { diez anos }\end{array}$ & $\begin{array}{l}\text { Tinha razoes para supor } \\
\text { que já se estava } \\
\text { acomodando a idade, } \\
\text { porque a sua filha Clara, } \\
\text { a mais nova, tinha dez } \\
\text { anos }\end{array}$ & $\begin{array}{l}\text { Tinha razoes para supor } \\
\text { que o amadurecimento a } \\
\text { aquietara, afinal, pois } \\
\text { sua filha Clara, a mais } \\
\text { nova, já estava com } 10 \\
\text { anos }\end{array}$ \\
\hline $\begin{array}{l}\text { La había ayudado a nacer } \\
\text { y ella era la única que } \\
\text { comprendía }\end{array}$ & $\begin{array}{l}\text { Tinha-a ajudado a nascer } \\
\text { e era a única pessoa que } \\
\text { compreendia }\end{array}$ & $\begin{array}{l}\text { Ajudara-a a nascer e, de } \\
\text { fato, era a única pessoa } \\
\text { que compreendia }\end{array}$ \\
\hline $\begin{array}{l}\text { Provocando [...] una } \\
\text { tormenta }\end{array}$ & $\begin{array}{l}\text { Provocando uma } \\
\text { tempestade }\end{array}$ & $\begin{array}{l}\text { Provocando uma } \\
\text { verdadeira tempestade }\end{array}$ \\
\hline $\begin{array}{l}\text { Conocía sus costumbres y } \\
\text { podía describir la forma }\end{array}$ & $\begin{array}{l}\text { Conhecia os seus } \\
\text { costumes e podia } \\
\text { descrever a maneira }\end{array}$ & $\begin{array}{l}\text { Conhecia seus costumes } \\
\text { e descreveria com } \\
\text { facilidade a maneira }\end{array}$ \\
\hline $\begin{array}{l}\text { Así como los ritos de } \\
\text { iniciación y los nombres } \\
\text { de las serpientes }\end{array}$ & $\begin{array}{l}\text { Assim como os ritos de } \\
\text { iniciação e os nomes das } \\
\text { serpentes }\end{array}$ & $\begin{array}{l}\text { Bem como seus ritos de } \\
\text { iniciação, e dominava } \\
\text { os nomes das serpentes }\end{array}$ \\
\hline $\begin{array}{l}\text { Sabía de los lamas que } \\
\text { toman té }\end{array}$ & $\begin{array}{l}\text { Sabia que os lamas } \\
\text { comem chá }\end{array}$ & $\begin{array}{l}\text { Sabia que os lamas } \\
\text { tibetanos tomam chá }\end{array}$ \\
\hline Se quedó en la casa & Ficou em casa & Barrabás ficou na casa \\
\hline $\begin{array}{l}\text { En aquella época todavía } \\
\text { no había vivido con una } \\
\text { mujer }\end{array}$ & $\begin{array}{l}\text { Nesse tempo não tinha } \\
\text { ainda vivido com uma } \\
\text { mulher }\end{array}$ & $\begin{array}{l}\text { Naquela época, porém, } \\
\text { não tinha ainda vivido } \\
\text { com uma mulher }\end{array}$ \\
\hline $\begin{array}{l}\text { No era enamoradizo, } \\
\text { nunca lo he sido, soy de } \\
\text { naturaleza fiel }\end{array}$ & $\begin{array}{l}\text { Não era namoradeiro, } \\
\text { nunca o fui, sou de } \\
\text { natureza fiel }\end{array}$ & $\begin{array}{l}\text { Não era namorador, } \\
\text { nunca fui; aliás, sou de } \\
\text { natureza fiel }\end{array}$ \\
\hline $\begin{array}{l}\text { Hacíamos un distingo } \\
\text { entre las mujeres } \\
\text { decentes y las otras }\end{array}$ & $\begin{array}{l}\text { Distinguíamos entre as } \\
\text { mulheres decentes e as } \\
\text { outras }\end{array}$ & $\begin{array}{l}\text { Distinguíamos as } \\
\text { mulheres descentes e as } \\
\text { outras }\end{array}$ \\
\hline $\begin{array}{l}\text { Porque no tengo ojo para } \\
\text { la ropa de mujer y porque } \\
\text { era tan hermosa }\end{array}$ & $\begin{array}{l}\text { Porque não tenho olhos } \\
\text { para roupa de mulher e } \\
\text { ela era tão formosa }\end{array}$ & $\begin{array}{l}\text { Porque não reparo em } \\
\text { roupa de mulher e } \\
\text { porque ela era tão } \\
\text { formosa }\end{array}$ \\
\hline $\begin{array}{l}\text { Decidí en ese mismo } \\
\text { momento }\end{array}$ & Decidi nesse momento & $\begin{array}{l}\text { Decidi naquele exato } \\
\text { momento }\end{array}$ \\
\hline $\begin{array}{l}\text { Tuve que saltar a la } \\
\text { vereda }\end{array}$ & $\begin{array}{l}\text { Tive que saltar para o } \\
\text { passeio }\end{array}$ & $\begin{array}{l}\text { Tive que pular do } \\
\text { bonde para a calçada }\end{array}$ \\
\hline Estaban ocupados & Estavam ocupados & $\begin{array}{ll}\text { Estavam } & \text { todos } \\
\text { ocupados }\end{array}$ \\
\hline $\begin{array}{l}\text { Eran más los que se } \\
\text { arruinaban que los que } \\
\text { triunfaban }\end{array}$ & $\begin{array}{l}\text { Eram mais os que se } \\
\text { arruinavam do que os } \\
\text { que triunfavam }\end{array}$ & $\begin{array}{l}\text { Eram mais numerosos } \\
\text { os que se arruinavam do } \\
\text { que os que triunfavam }\end{array}$ \\
\hline
\end{tabular}

Primeiramente em relação aos acréscimos, ocorre que, dentre os 16 casos expostos, em 13 a T2 acrescenta algum termo à estrutura. A T1 em nenhum momento fez acréscimos no capítulo estudado. Os acréscimos na T2 são referentes a palavras que demonstram uma conclusão mais explícita (afinal, de fato), uma ênfase (verdadeira, com facilidade, dominava, todos, numerosos), a palavras já conhecidas e que sua ausência não causava desentendimento,

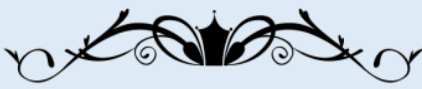




\section{Revista Letras Raras}

ISSN: 2317-2347 - Vol. 8, Ano 4, № 3 - 2015

mas que o tradutor optou por acrescentar (Barrabás, bonde), e a uma especificação do termo "lamas" (tibetanos). Como afirmado anteriormente, a T1 não efetuou nenhuma adição, porém eliminou dois termos (que voltaram a aparecer na T2).

Quadro 7 - Categoria nomes próprios

\begin{tabular}{ll|ll|ll}
\hline \multicolumn{4}{c}{ Quadro 8- Categoria nomes próprios (continua) } \\
\hline Nana & \multicolumn{1}{c}{ T1 } & \multicolumn{3}{c}{ T2 } \\
\hline $\begin{array}{l}\text { Parroquia de San } \\
\text { Sebastián }\end{array}$ & Ama & $\begin{array}{l}\text { Paróquia de San } \\
\text { Sebastian }\end{array}$ & $\begin{array}{l}\text { Paróquia } \\
\text { Sebastião }\end{array}$ & de & São \\
\hline San Sebastián & São Sebastião & São Sebastião & \\
\hline Nicolás & Nicolau & Nicolás & \\
\hline El Callao & El Callao & Callao & \\
\hline Guayaquil & Guayaquil & & Guaiaquil & \\
\hline
\end{tabular}

Nessa categoria, em particular, todos os termos do TF estão destacados, e nas colunas das (re)traduções estão destacados somente os termos que não foram traduzidos, isto é, que estão da mesma forma que no TF. Faz-se necessário observar que o termo "São Sebastião" na terceira linha foi traduzido da mesma forma nas duas traduções. Sua presença no quadro se deve ao fato de que ele foi traduzido dessa forma apenas quando referente à pessoa, ao santo. $\mathrm{Na} \mathrm{T} 1$, quando se refere à paróquia de mesmo nome, o tradutor manteve o nome em espanhol, enquanto na T2 ocorreu a tradução do termo. À exceção do nome do santo, que foi traduzido, a T2 manteve os nomes dos outros dois personagens, e aportuguesou os nomes das regiões, enquanto a T1 traduziu os nomes de pessoas e manteve os nomes dos locais. Vale aqui também assinalar que os demais nomes próprios do trecho selecionado do livro não foram traduzidos em nenhuma das duas traduções.

Esta é a categoria mais acirrada e não proporciona muitos dados para uma análise mais robusta, mas configura-se num elemento importante a se considerar quando o tema é domesticação ou estrangeirização. Nos seis exemplos, a T1 se aproxima do TF em três casos e a T2 em dois. Porém, se for considerado o fato de que o nome da personagem "Nana" ocorre inúmeras vezes ao longo de todo o capítulo, tem-se que a tradução do termo por Ama (T1) se afasta mais do TF.

Com relação à última categoria analisada, ou seja, a das traduções divergentes, um número altíssimo de exemplos foi encontrado. O Quadro 7 a seguir traz somente parte destes exemplos. 


\section{Revista Letras Raras}

ISSN: 2317-2347 - Vol. 8, Ano 4, № 3 - 2015

Quadro 9 - Categoria traduções divergentes.

\begin{tabular}{|c|c|c|}
\hline \multicolumn{3}{|c|}{ Quadro 10 - Categoria traduções divergentes (continua) } \\
\hline TF & T1 & $\mathbf{T 2}$ \\
\hline $\begin{array}{l}\text { Sobrevivir a mi propio } \\
\text { espanto }\end{array}$ & $\begin{array}{l}\text { Sobreviver a meu próprio } \\
\text { espanto }\end{array}$ & $\begin{array}{l}\text { Sobreviver a meu próprio } \\
\text { terror }\end{array}$ \\
\hline $\begin{array}{l}\text { Aquel era un día aburrido } \\
\text { y otoñal }\end{array}$ & $\begin{array}{l}\text { Era um dia aborrecido e } \\
\text { outonal }\end{array}$ & $\begin{array}{l}\text { Era um monótono dia de } \\
\text { outono }\end{array}$ \\
\hline $\begin{array}{l}\text { Pudieran contrarrestar } \\
\text { ese lamentable efecto }\end{array}$ & $\begin{array}{l}\text { Pudessem contrastar } \\
\text { com esse lamentável } \\
\text { efeito }\end{array}$ & $\begin{array}{l}\text { Pudesse atenuar esse } \\
\text { lamentável efeito }\end{array}$ \\
\hline Sus elaboradas pelucas & $\begin{array}{l}\text { Com complicadas } \\
\text { cabeleiras }\end{array}$ & $\begin{array}{l}\text { Suas } \\
\text { cabeleiras }\end{array}$ \\
\hline $\begin{array}{l}\text { Vestuarios de nobles } \\
\text { florentinos }\end{array}$ & $\begin{array}{l}\text { Vestuário de nobres } \\
\text { florentinos }\end{array}$ & $\begin{array}{l}\text { Trajes de } \\
\text { florentinos }\end{array}$ \\
\hline $\begin{array}{l}\text { Cuerpo torcido en una } \\
\text { postura indecente }\end{array}$ & $\begin{array}{l}\text { Corpo torcido numa } \\
\text { postura indecente }\end{array}$ & $\begin{array}{l}\text { Corpo retorcido em } \\
\text { postura indecorosa }\end{array}$ \\
\hline $\begin{array}{l}\text { Incitara a la lujuria yal } \\
\text { olvido }\end{array}$ & $\begin{array}{l}\text { a luxúria e ao } \\
\text { eento }\end{array}$ & $\begin{array}{l}\text { Incitasse à luxúria e à } \\
\text { distração }\end{array}$ \\
\hline $\begin{array}{l}\text { La mayor tristeza y } \\
\text { castidad }\end{array}$ & tristeza e & $\begin{array}{l}\text { xima tristeza e } \\
\text { ade }\end{array}$ \\
\hline Esponjosas tortillas & rtilhas & Delicadas omeletes \\
\hline $\begin{array}{l}\text { El sacerdote estaba } \\
\text { provisto }\end{array}$ & $\begin{array}{l}\text { erdote estava } \\
\text { lo }\end{array}$ & O sacerdote era provido \\
\hline $\begin{array}{l}\text { Fingía afanarse en una } \\
\text { pelusa de su solapa }\end{array}$ & $\begin{array}{l}\text { Fingia preocupar-se } \\
\text { com qualquer cisco na } \\
\text { lapela }\end{array}$ & $\begin{array}{l}\text { Simulava ocupar-se } \\
\text { com qualquer cisco em } \\
\text { sua lapela }\end{array}$ \\
\hline Para no darle la cara & Para esconder a cara & Para não o encarar \\
\hline $\begin{array}{l}\text { Abría los } \\
\text { sorprendida }\end{array}$ & $\begin{array}{l}\text { Abria os olhos } \\
\text { surpreendida }\end{array}$ & $\begin{array}{l}\text { Arregalava os olhos, } \\
\text { espantada }\end{array}$ \\
\hline $\begin{array}{l}\text { Sacudidos por vientos de } \\
\text { modernismo }\end{array}$ & $\begin{array}{l}\text { Sacudidos por ventos de } \\
\text { modernismo }\end{array}$ & $\begin{array}{l}\text { Arejados pelos ventos } \\
\text { da modernidade }\end{array}$ \\
\hline $\begin{array}{lr}\text { Suplicios } & \text { que } \\
\text { incorporaba en cada } \\
\text { sermón para sembrar el } \\
\text { terror de Dios }\end{array}$ & $\begin{array}{l}\text { Suplícios que introduzia } \\
\text { em cada sermão para } \\
\text { espalhar o terror a Deus }\end{array}$ & $\begin{array}{l}\text { Suplícios que } \\
\text { incorporava a cada } \\
\text { sermão para espalhar o } \\
\text { temor a Deus }\end{array}$ \\
\hline
\end{tabular}

Em relação aos números totais (95 amostras), a T1 aproximou-se mais do TF em 82 casos, contra apenas 13 da T2. Talvez o fato que chame mais atenção num primeiro momento é que a T1 muitas vezes mantém a mesma palavra do TF, por ambas existirem em espanhol e em português, enquanto a T2 utiliza uma palavra sinônima ou de significado semelhante. Os exemplos a seguir encontram-se na mesma ordem das colunas dos quadros, ou seja, TF, T1 e $\mathrm{T} 2$.

- Espanto - espanto - terror

- Vestuario - vestuário - trajes

- Torcido - torcido - retorcido

- Indecente - indecente - indecorosa

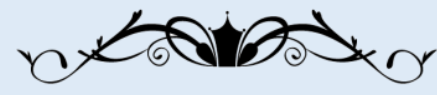




\section{Revista Letras Raras}

ISSN: 2317-2347 - Vol. 8, Ano 4, № 3 - 2015

- Modernismo - modernismo - modernidade

- Esposa - esposa - mulher

- Matrimonio - matrimônio - casamento

- Corredor-corredor - alameda

- Nunca-nunca-jamais

- Vivía - vivia - morava

Estes são os exemplos, respectivamente, do TF, da T1 e da T2. No entanto, ocorreu também de a T1 utilizar um termo diferente, e a T2 retomá-lo:

- Elaboradas - complicadas - elaboradas

Outro caso semelhante a este são as traduções literais. Há inclusive casos em que as palavras no TF e na T1 possuem o mesmo radical em ambas as línguas. Seguindo a arrumação anterior, têm-se os seguintes exemplos:

- Aburrido - aborrecido - monótono

- Olvido - esquecimento - distração

- Mayor-maior - máxima

- Asombrosa - assombrosa - fantástica

- Loza-louça-porcelana

- Los esposos - os esposos - o casal

- Criollo - crioulo - mestiço

- Distracción - distração - passatempo

- Llevaba - levava-usava

- Un par-um par-duas

- Más Allá - Mais Além - Além

- Al nacer - ao nascer - quando nasceu

Em 100\% dos exemplos a T1 se aproximou mais do TF neste aspecto estrutural. Abrangendo agora a análise a estruturas maiores, com mais de um termo, e contendo expressões idiomáticas, temos os seguintes exemplos:

- Era evidente - era evidente - evidenciavam

- Terminara de una vez - Terminasse de vez - encerramento

- De domingo - domingueira - de domingo

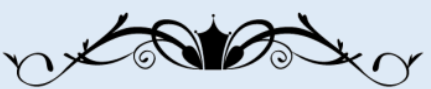




\section{Revista Letras Raras}

ISSN: 2317-2347 - Vol. 8, Ano 4, № 3 - 2015

- Del agua - aquático - da água

- Tinta china - tinta-da-china - nanquim

- De indios - de índios - indígenas

- Ser rechazado - ser repelido - rejeição

- Mandaba a hacer - mandava fazer - encomendava

- Con el tiempo - com o tempo - posteriormente

- No tengo ojo - não tenho olhos - não reparo

E algumas estruturas mais extensas:

- Pendiente de las mujeres - dependente das mulheres - mulherengo

- Hicieron su agosto - fizeram seu negócio - tiraram a barriga da miséria

- Tenía los retozos - tinha brincadeiras - em suas travessuras lembrava

- En ese estado - nesse estado - com essa característica

- Tenían nada que ver - nada tinham a ver - não estavam envolvidos

- Era que no tenía - era que não tinha - consistia no fato de não ter

- Clara era la preferida de la Nana - A Ama preferia Clara - Clara era a preferida da Nana

É possível observar, mais uma vez, que a T1 tende a uma tradução mais literal, enquanto a T2 busca palavras e construções mais próximas do português. Dizer que um dia é "monótono" em vez de "aborrecido" é um exemplo disso. Utilizar o verbo "usar" no lugar de "levar" quando referente a uma roupa que está vestida no corpo também corrobora esta ideia; embora haja novamente algumas ocasiões em que o tradutor realiza uma mudança na T1, mas volta à estrutura do TF na T2, como em "de domingo", "da água”, e no último exemplo, em que toda a estrutura é retomada: "Clara era a preferida da Nana".

Continuando por uma perspectiva não só estrutural, mas também semântica, têm-se as seguintes amostras:

- Alfombras - almofadas - tapetes

- Novelas románticas - novelas românticas - romances açucarados

Nestes dois casos não há diferença linguística. Ambas as traduções mantiveram a ordem, a classe gramatical e o número de palavras. O que se observa são traduções com significados diferentes, em que a T1 aproxima-se mais do TF por manter as mesmas palavras

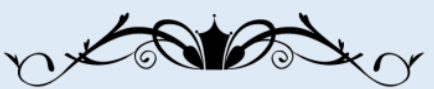




\section{Revista Letras Raras}

ISSN: 2317-2347 - Vol. 8, Ano 4, № 3 - 2015

(novelas románticas) e por optar por um termo foneticamente mais próximo de "alfombra". Quanto ao primeiro exemplo, talvez a fonética seja a justificativa pela palavra "almofada", ou o tradutor naquele primeiro momento teve essa interpretação. Já na T2, o termo é traduzido pela tradução mais usual, que é "tapete".

No segundo caso, novela e romance são gêneros literários diferentes, embora tenham suas semelhanças. Na primeira tradução, o tradutor não viu necessidade de mudar esses termos. Já em sua retradução, foram utilizados o gênero "romance" e o adjetivo "açucarados", este último com o intuito de evitar a ocorrência muito próxima de vocábulos muito semelhantes, como em "romances românticos". Algo em sua interpretação motivou a mudança nas expressões.

\section{Considerações finais}

Realizando uma síntese do que foi comentado no capítulo anterior, com base no total de exemplos em cada categoria, tem-se que: (i) na categoria numeral, a T1 aproximou-se mais do TF em 100\% dos casos; (ii) na categoria advérbios que terminam em -MENTE, o T1 aproxima-se mais do TF em 87,5 \% dos casos; (iii) com os nomes próprios, considerando apenas a tabela, tem-se um empate. Porém, levando-se em consideração a questão da personagem Nana, que aparece incontáveis vezes ao longo do capítulo (e do livro também), é possível concluir que neste caso a T2 está mais próxima do TF; (iv) no quesito inversões, a aproximação do T1 ao TF acontece em aproximadamente $77 \%$ das amostras; (v) quanto às omissões e aos acréscimos, o T1 aproxima-se do TF também em 87,5\%; (vi) e em relação às traduções divergentes, o T1 aproximou-se mais do TF em aproximadamente $86 \%$.

É conveniente recordar que, devido ao fato de todos os exemplos entre T1 e T2 serem diferentes, a soma do percentual de cada tradução totaliza $100 \%$. Isto significa que, se na categoria advérbio $87,5 \%$ corresponde à maior proximidade do $\mathrm{T} 1$ ao $\mathrm{TF}, \mathrm{o} T 2$ aproximouse mais do TF em $12,5 \%$ dos casos nessa mesma categoria.

Mesmo indo além dos números, como foi comentando anteriormente, as estruturas e o léxico da T1 estão mais próximos do TF que a estrutura geral da T2. O que ocorreu no caso das traduções publicadas foi que o tradutor se manteve mais preso à estrutura do original e da língua espanhola na primeira tradução, enquanto na tradução posterior realizou muitas mudanças, possivelmente motivadas pelas mudanças que ocorreram na língua portuguesa, por

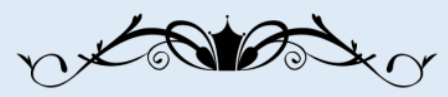




\section{Revista Letras Raras}

ISSN: 2317-2347 - Vol. 8, Ano 4, № 3 - 2015

talvez por ter tido mais tempo para refletir sobre a tradução, ou por exigências da editora. É possível que o tradutor tenha tido a "falha" que Berman $(1990,2007)$ menciona atenuada, e conseguiu realizar uma tradução que ele próprio acreditasse ser mais adequada, e mais fiel semanticamente, retomando, assim, os significados do TF.

Conclui-se, por esta pesquisa, que a hipótese da retradução está longe de poder ser aplicada por um viés estritamente linguístico. Segundo tal hipótese, a primeira tradução deveria se distanciar mais do original, mas o que ocorreu foi o contrário: a T1 tendeu muito mais a obedecer à estrutura do original do que a tradução posterior. Entretanto, com a análise semântica breve e superficial realizada, foi possível admitir a possibilidade de a hipótese da retradução se confirmar neste outro aspecto.

É possível também realizar uma comparação por outros vieses, como fizeram Dastjerdi e Mohammadi (2013) em seus estudos estilísticos de uma retradução de Orgulho e Preconceito. Desta forma, convergimos com os estudos propostos por estes e por SusamSarajeva (2003), os quais apontam a importância de mais estudos empíricos comparativos em tradução, tomando por base ora a semântica, ora a estilística, ora a estrutura e assim por diante.

A literatura é uma linguagem independente, que possui sua vida própria. À medida que traduções de uma mesma obra vão aparecendo, há maiores possibilidades de se interpretar o texto de acordo como o autor da obra a pensou ou como desejam as editoras. Portanto, o fato de, no nosso trabalho, a T1 estar mais próxima ao TF que a T2 não quer dizer que esta última não tenha alcançado maior proximidade, seja semântica, seja estilística - vieses que não fazem parte do escopo deste trabalho.

De uma forma ou de outra, nossa proposta não passa por juízo de valor, é somente uma tentativa mais de se indagar a hipótese da retradução e averiguar se ela encontra respaldo, conforme outros estudos anteriormente publicados, desta vez, tendo o par linguístico espanhol-português como protagonista da análise.

\section{Referências}

ALLENDE, I. La casa d los Espíritus. La habana: Casa de las Américas, 1982. A casa dos Espíritos. Tradução de Carlos Martins Pereira, $3^{a}$ edição. São Paulo:

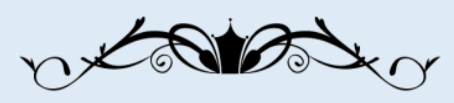




\section{Revista Letras Raras}

ISSN: 2317-2347 - Vol. 8, Ano 4, № 3 - 2015

DIFEL, 1982.

. A casa dos Espíritos. Tradução de Carlos Martins Pereira, 43ª edição. Rio de janeiro: Bertrand Brasil, 2013.

BAKER, M.; MALMKJAER, K. Routledge encyclopaedia of translation studies. 1. ed. Londres: Routledge, 1998.

BERMAN, A. A tradução e a letra ou O albergue do longínquo. Trad. Marie-Hélène Catherine Torres et al. Rio de Janeiro: 7Letras, 2007.

. La retraduction comme espace de traduction. Palimpsestes, v. 13, 1990. p. 1-7.

Bensimon, P. Presentation. Palimpsestes, n. 4, p. ix-xiii, 1990.

CATFORD, J. C. Uma Teoria linguística da tradução. São Paulo: Cultrix, 1980. Tradução do Centro de Especialização de Tradutores de Inglês do Instituto de Letras da Pontifícia Universidade Católica de Campinas

DASTJERDI, H. V.; MOHAMMADI, A. Revisiting "Retranslation Hypothesis": A Comparative Analysis of Stylistic Features in the Persian Retranslations of Pride and Prejudice. Open Journal of Modern Linguistics, v. 3, n. 3, p. 174-181, 2013.

DEANE, S. L. Confronting the retranslation hypothesis: flaubert and sand in the British literary system. 308 f. Tese (Doutorado) - University of Edimburgh, Edimburgo, 2011.

DESMIT, I. (Re)translation revisited. Meta: Journal des Traducteurs, v. 54, n. 4, p. 669-683, 2009.

GAMBIER, Y. La retraduction, re tour et tour. Meta 39, p. 413-417, 1994.

HOLMES, J. S. . The Name and Nature of Translation Studies. In: James S. Holmes, Translated! Papers on Literary Translation and Translation Studies, Amsterdam: Rodopi, 1977/1998, pp. 67-80.

KENNY, D. Unit of translation. In BAKER, M. ,SALDANHA, G. (Ed.) Routledge encyclopedia of translation studies. 2.ed. Nova Iorque: Routledge, 2009.

MALTA, G. O processamento cognitivo em tarefas de (re)tradução: um estudo baseado em rastreamento ocular, registro de teclado e mouse e protocolos retrospectivos. Tese (doutorado em Linguística Aplicada) 249f. Belo Horizonte: Faculdade de Letras/Universidade Federal de Minas Gerais, 2015.

O'DRISCOLL, K. Around the world in eighty changes: a diachronic study of the multiple causality of six complete translations (1873-2004), from French to English, of Jules Verne's novel. 2009. Tese (Doutorado em Filosofia). School of Applied Language and Intercultural Studies (SALIS), Faculty of Humanities and Social Sciences, Dublin City University, Dublin, 2009

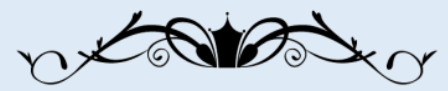




\section{Revista Letras Raras}

ISSN: 2317-2347 - Vol. 8, Ano 4, № 3 - 2015

PAGANO, A.; VASCONCELlOS, M. L. Estudos da tradução no Brasil: reflexões sobre teses e dissertações elaboradas por pesquisadores brasileiros nas décadas de 1980 e 1990 . DELTA, São Paulo, v. 19, n. spe, 2003.

PALOPOSKI, O.; KOSKINEN, K. A thousand and one translation: revisinting retranslation. In: HANSEN, G.; MALMKJAER, K.; GILE, D (Eds.). Claims, changes and challenges in translation studies: selected contributions from the EST Congress. Amsterdan: John Benjamim, 2001. p. 27-38.

PALOPOSKI, O.; KOSKINEN, K. Reprocessing texts: the fine line between retranslating and revising. Across languages and cultures, v. 11, n. 1, p. 29-49, 2010.

PYM, A. Method in translation history. Maschester: St. Jerome, 1998.

SUSAM-SARAJEVA, S. Multiple-entry visa to travelling theory. Retranslations of literary and cultural theories. New York: Rodopi, 2003.

TAHIR-GÜRÇALAR, S. Retranslation. In: BAKER, M.; MALMKJAER, K. Routledge encyclopaedia of translation studies. 1. ed. Londres: Routledge, 1998. p. 125-127.

TOURY, G. Descriptive Translation Studies and beyond. Amsterdam / Philadelphia: John Benjamins, 1995.

VINAY, J. P.; DARBELNET, J. Stylistique comparée Du français et de l'anglais: méthode de traducción. Paris: Didier, 1977

Recebido em: 25/08/2015

Aceito em: 09/12/2015 